\title{
Fuzzy AHP Approach to Prioritizing the Critical Success Factors of Organizational Culture
}

\author{
Nihan Çağlayan¹, Abdullah Yildizbaşi², Babak Daneshvar Rouyendegh (Babek \\ Erdebilli) ${ }^{2 *}$ \\ ${ }^{1}$ Department of the Management and Organization, Kırsehir Ahi Evran University, Kırşehir, Turkey \\ ${ }^{2}$ Department of Industrial Engineering, Ankara Yıldırım Beyazıt University, Ankara, Turkey
}

\begin{abstract}
Keywords:

Multi Criteria Decision

Making, FAHP,

Organizational Culture

Received

26 September 2018

Received in revised form

21 December 2018

Accepted

21 December 2018

Correspondence:

babek.erdebilli2015@gmail.com

The world that we live in where the social and organizational life rapid social and cultural transformations are experienced, and the intensities of change and competition are intensely perceived has a dynamism. In this dynamism, every human being is a part of an organization. In these organizations, there is a culture which is defined in various ways by various thinkers and it is a rather complex concept. However, all definitions have reached the conclusion that the culture is a common entity shared with a community. In the 1980s, the concept of organizational culture has emerged. While many formal definitions exist, organizational culture is basically a term used to describe the environment where people work and the influence it has on how they think, act, and experience work. Therefore, organizational culture is stated as a system of values, behaviors, habits, norms, beliefs and that direct the behaviors of individuals in an organization. As each individual has a unique personality, every organization has its own personality that distinguishes it from other organizations. Hence, organizational culture consists of several abstract and complementary factors. Literature has shown that there are many factors affecting the success of organizational culture. The prioritization of these factors for the organizations and the effective use of the available resources are gaining importance at this stage. At this stage, different approaches are taken in the literature to prioritize and sort the criteria. MCDM approach which is one of the most prominent approaches was used in this study. The proposed approach was tested based on the opinions of the decision makers and the results were shared.
\end{abstract}

(C)AIMI Journals

Every organization has own unique structure just like humans that show the organizational culture. In these organizations, there are many people who are influenced by these organizations and they behave depending on these organizations. These organizations which 
have varied cultures affect the employee and they behave depending on these cultures. Therefore, this organizational culture is unwritten rules. These rules determine how to act, how to study, and what to wear, etc. The expectation of the customer / business or necessity of the market has an effective role in the organizational culture.

The organizational culture demonstrates the expectancy, value, the vision and similar characteristic of an organization. There can be many various situations that affect the reliability, efficiency, productivity, and quality. The way employees think and behave is related to the organizational culture. When the structure of an organization changes, it is very considerable for the people in the organization to keep up with this structure. With today's increasing competition, the more imaginative, variable, effective and influential an organization is the stronger the organism structure is.

Since the 1980s, the organizational culture has been one of the major topics in literature. Nowadays, the topic of organizational culture is extensively studied in management, psychology, business, and many similar fields. In 2007, for the health service, how to reduce medical errors with specific management techniques and organizational culture was studied (Stock, McFadden, \& Gowen, 2007). One of the most widespread cases in the construction sector is the delay and the relationship with the organizational culture that has been studied (Arditi, Nayak, \& Damci, 2017).

\section{Literature Review}

An organization is a group of people who change. This change might be in hierarchy, technology, and networks. These structural changes are related to changes of the employees' psychology. The Organizational culture, on the other hand, connects the firm's beliefs, values, and discipline (Schneider, Brief, \& Guzzo, 1996). Therefore, the organizational culture plays a crucial role in the organization's effectiveness and performance, and this can differ from other organizations.

Anna, Igor, and Natalia (2015) examined changing the legal, economic situation, and norms in the activities of universities within the scope of higher education reforms in Russia. The study was applied to 15 Russian universities. Fifteen academic staff including assistants, faculty members, teachers, and their seniors, Associate Professors and Professors participated in their study. Questionnaire was used to collect data. The official survey form comprises a barrier: one question and four alternative answers (clan, adhocracy, hierarchy, and market). It is necessary to distribute points (100 total) between the two alternatives of the "now" and "preferred" columns. The Russian higher education institutions that wish to compete with other international universities should examine all the organizational factors. The organizational factors have been considered in different papers as well (Acar, 2012; Aktaş, Çiçek, \& Kiyak, 2011; Arditi, Nayak, \& Damci, 2017; Stock, McFadden, \& Gowen, 2007).

Belias, Koustelios, Vairaktarakis, and Sdrolias (2015) examined the relationship between job satisfaction and organizational culture of a banking institution in Greek. The study was applied on Greek banking employees. The study includes six main questions, and each question has four alternatives. As a result, the participants were satisfied with their work. According to the organizational culture type, it is difficult to identify any other aspect of job satisfaction. Therefore, in the future work, it needs to consider the other factors which can influence an 
individual's perceptions of organizational culture. The aim of this study was to analyze the motivational dynamics of employee and also the employees' relations to their sector.

There is another research that is handled in ((Panagiotis, Alexandros, \& Polychronopoulos, 2014) the administrative offices of the City of Zografou. The questionnaire was completed by 50 administrative authorities of Zografou Municipality. For examining the organizational cultures, Cameron and Quinn's model was used and four group (Clan, Adhocracy, Market, and Hierarchy) and four different motivation factors (rewards, collegiality, working properties, and achievements) were considered. The questionnaire included six factors examining the organizational culture such as strategic point, success criteria and procedure of management. According to the results, the Clan which is positively connected with reward and working properties factors and Adhocracy culture type which is fully connected with rewards and achievement factors are the most dominant.

Iljins, Skvarciany, and Gaile-Sarkane (2015) investigated the effect of organizational culture on climate in the duration of change. About 100 people in two different manufacturing companies participated in this study. There are five organizational culture factors. Ten expert participants took part in the survey. The results indicated that employee satisfaction is the first main factor for variation. The employees who are unsatisfied do not encourage, even resist variations.

Henri (2006) studied the relationships between organizational culture and the characteristics (control and flexibility) of the performance measurement system (PMS). In this paper, the questionnaire was developed for the firm whose selection was applied based on the two measures. Totally, 383 filled questionnaires were received. The results showed that the flexible value firms are more likely to integrate PMS into their enterprise processes and use more performance indicators. PMS is used by companies to promote and direct innovation, creativity, change, and learning.

Lapiņa, Kairiša, and Aramina (2015) stated that "organizational culture is a complex pattern of assumptions about the group's place and function in the world. Organizational culture is directly connected with effectiveness and performance of the organization - the stronger is the organizational culture, the more effective is the organization". Lapina et al. (2015) studied the perspective of management and organizational culture, and sustained development of the Riga Technical University. Organizational Culture Assessment Instrument (OCAI) questionnaire was applied and included the factors of qualities, leadership in the organization, human resources management, organizational unity, strategic goals, and criteria of success. The study led to the creation of organizational culture characteristics and the analysis of factors affecting the development of organizational culture. The University concluded that the organizational culture is the basis for quality management and is directly linked to development.

Rus and Rusu (2015) examined the organizational culture in public and private organizations. To this end, a questionnaire including ten questions was applied. Totally, 170 respondents with different ages, positions and status participated in this study. Results of this study showed that private company has rational market-oriented culture type whose main performance criteria is efficiency; on the other hand, for the public institution, the manager's significant role plays a crucial role to shape the organizational culture. 
In the literature, more specifically, the organizational culture has been studied deeply such as the relationship between an office layout features and organizational culture. Office layout and organization culture have significant effects on employees. Zerella, von Treuer, and Albrecht (2017) investigated the relationship between official layout features and organizational culture. In the paper, there are two main objectives which are analyzing the relationship between organizational culture and office layout, whether or not the organization culturally intervenes the relation among office order and job satisfaction. To do so, some factor analyses were conducted such as Exploratory Factor Analysis for office layout, Organizational Climate Measure and Organizational Climate Questionnaire for organizational culture. Totally, 202 participants were participated in the survey. This study found that office orientation characteristics were a positive effect of the clan culture style on the working perception, and that the working sense of the clan culture style influenced the relation among office characteristics and job satisfaction. And also results have strengthened the theory that office order is an institutional cultural indicator that can guide employees' behavior, especially in terms of how people interact.

Decision making is a big step in the problems. Expressing the resolution of our decision can be quantitative and qualitative or both. In the literature, deciding can be expressed by some methods called Multiple Criteria Decision Analysis Methods (MCDM). These methods have increasingly used in last decades in real world problems and review articles have dealt with applications and techniques of MCDM (Mardani et al. 2015). Some of the most known methods have similarities in use like AHP, ANP, and TOPSIS. These methods can be used in different fields (logistic, health, supply chain, manufacturing, economy etc.). From the most recent studies using the multi criteria decision methods, the successful portfolio selection was used by Pätäri, Karell, Luukka, and Yeomans (2018). In this study, MS, AHP, TOPSIS, DEA have been operated to join value at a single productivity score. Results of the study demonstrated that examined MCDM can be successfully carried out to stock portfolio selection. The MCDM investigated can successfully be implemented to equity portfolio selection. Also, MCDM is used for determination of the situation in natural events, and decisions on evaluation.

In order to monitor and analyze the risk maps of the earthquake disaster, and the potential loss evaluation, the case study was conducted in İstanbul in 2018 (Nyimbili, Erden, \& Karaman, 2018). In this study, AHP and TOPSIS methods were used with five criteria (field topography, source to site distance, soil classification, liquefaction potential, fault/focal mechanism). Based on the results, these methods are extremely recommended for diminishing the time for analysis of earthquake hazards and preparing more accurate hazard map. Mankind mistake is one of the widespread factors contributing to the events happening in complex systems and most of the accidents. To measure the importance of the error factors, AHP and fuzzy TOPSIS are used in emergency departments in Taiwan (Hsieh et al., 2018).

\section{Method}

As discussed above, there are various studies on difficulties in organizational culture. However, there is no practice classifying or arranging these difficulties by importance level. The question that arises at this point regarding the organizational culture is that what can be done to 
prioritize the criteria that affect the organizations success. In this study in order to prioritize the criteria Fuzzy AHP method is used.

\section{Fuzzy AHP}

AHP is one of the quantitative method which designs multi person problem hierarchically, solutions thus are simplified. Also, this technique is effective for both qualitative and quantitative data; however, this method cannot reflect the human thinking style. The decision maker will often find it more reliable to make intermittent assessments rather than to make definitive assessments.

For this reason, fuzzy AHP is developed to handle the hierarchical fuzzy issues. In the fuzzy AHP method, there are some steps to solve the problem. There are different techniques to decide the relative importance weights for criteria. In the present study we used Buckley's method to determine the fuzzy priorities of comparison ratios with triangular membership functions. The procedure is as follows:

Step 1: Decision Makers compare the criteria and sub-criteria in terms of linguistic term, and its triangular fuzzy scale which are demonstrated in Table 1.

Table 1

Linguistic Variables for Rating the Weights of Criteria

\begin{tabular}{lll}
\hline Linguistic terms & Triangular fuzzy scale & Triangular fuzzy reciprocal scale \\
\hline Equally importance & $(1,1,1)$ & $(1 / 1,1 / 1,1 / 1)$ \\
Moderate importance & $(1,3,5)$ & $(1 / 5,1 / 3,1 / 1)$ \\
Demonstrated importance & $(5,7,9)$ & $(1 / 9,1 / 7,1 / 5)$ \\
Extreme importance & $(7,9,9)$ & $(1 / 9,1 / 9,1 / 7)$ \\
& $(1,2,3)$ & $(1 / 3,1 / 2,1)$ \\
Intermediate values & $(3,4,5)$ & $(1 / 5,1 / 4,1 / 3)$ \\
& $(5,6,7)$ & $(1 / 7,1 / 6,1 / 5)$ \\
& $(7,8,9)$ & $(1 / 9,1 / 8,1 / 7)$ \\
\hline
\end{tabular}

For example, if Criteria 1 has demonstrated importance with Criteria 2, then Criteria 1 takes the triangular fuzzy scale as $(5,7,9)$; on the other hand, its triangular fuzzy reciprocal scale is $(1 / 9,1 / 7,1 / 5)$.

The pair wise contribution matrices is demonstrated in the following equation where the $\frac{1}{12}$ shows the decision maker 1's choice of first criterion over second criterion.

$$
A^{k}=\left[\begin{array}{cccc}
d_{11}^{k} & d_{12}^{k} & & \\
d_{21}^{k} & d_{22}^{k} & & d_{2 n}^{k} \\
d_{2 n}^{k} & \vdots & \ldots & \vdots \\
d_{m 1}^{k} & d_{m 2}^{k} & \cdots & d_{m}^{k}
\end{array}\right]
$$

Step 2: If there is more than one decision makers, the average calculation of choices of decision makers ( ${ }^{2}$ ) is made as in Eq.2. 
$d_{i f}=\frac{\sum_{i= \pm}^{K} d_{t i}^{2}}{E}$

Step 3: Pair wise contribution matric is updated depending on the averaged choices.

$$
F=\left[\begin{array}{ccc}
d_{11} & \cdots & d_{1 n} \\
i & \cdots & i \\
d_{n 1} & \cdots & d_{n n}
\end{array}\right]
$$

Step 4: Geometric mean is calculated for fuzzy comparison values of all criteria according to Buckley in the following equation. Note that $\tilde{r}_{i}$ is still triangular value.

$\eta=\left(\prod_{f=1}^{n} d_{i j}^{n}\right)^{1 / n}, t=1,2, \ldots, n$

Step 5: For finding the fuzzy weight of criterion in the following equation and the steps should be calculated.

1. Vector summation for every $\tilde{r}_{i}$ is found.

2. reverse of vector summation is found then modify the fuzzy triangular number.

3. $\tilde{r}_{i}$ is multiply with reverse vector in order to get fuzzy weight of criterion.

$\tilde{w}_{t}=\tilde{r}_{t} \otimes\left(\tilde{r}_{1} \oplus \tilde{r}_{2} \oplus \tilde{r}_{3} \oplus \ldots \ldots \oplus \tilde{r}_{n}\right)^{-1}$

Step 6: The average of the fuzzy weight of the criterion is found.

$M_{i}=\frac{w w_{t}+m w_{t}+w w_{i}}{g}$

Step 7: $M_{i}$ is still non-fuzzy number, normalization is needed.

\section{Definition of Criteria}

Therefore, the criteria and sub-criteria have to be decided for decision making on factors affecting organizational factors. According to literature, the most effective factors are presented in Table 2. 
Table 1

Evaluation Criterion of Organizational Culture

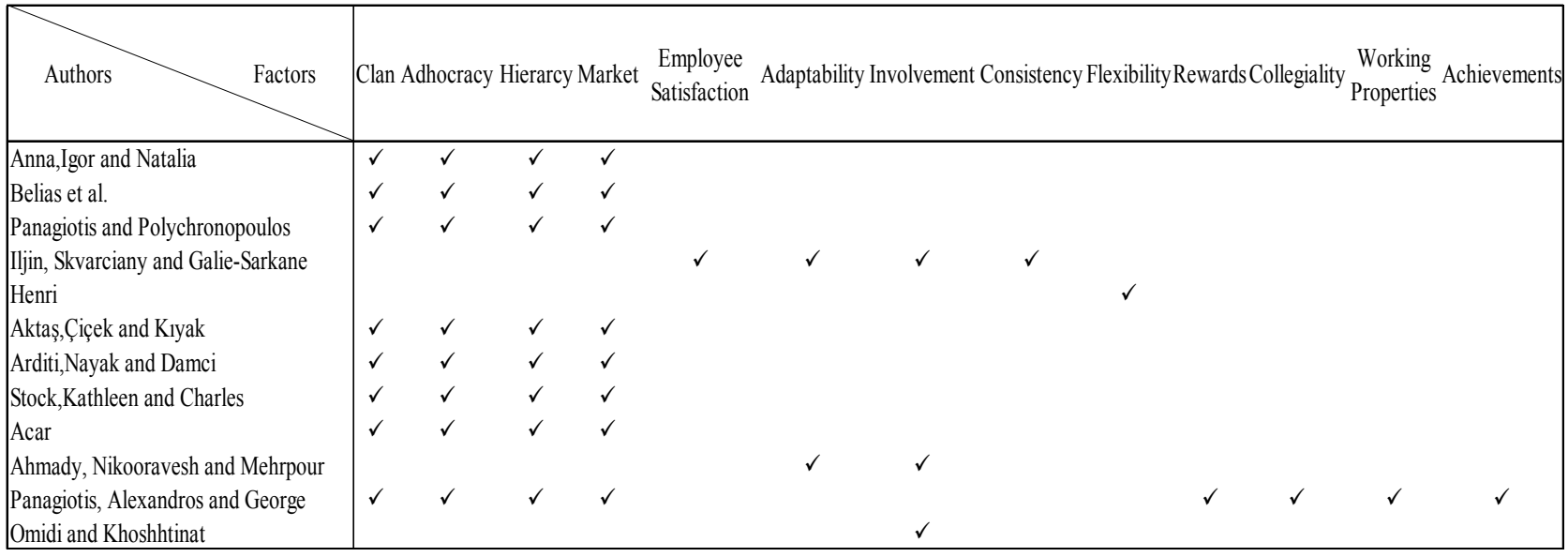

The criteria and sub-criteria are demonstrated in Figure 1.

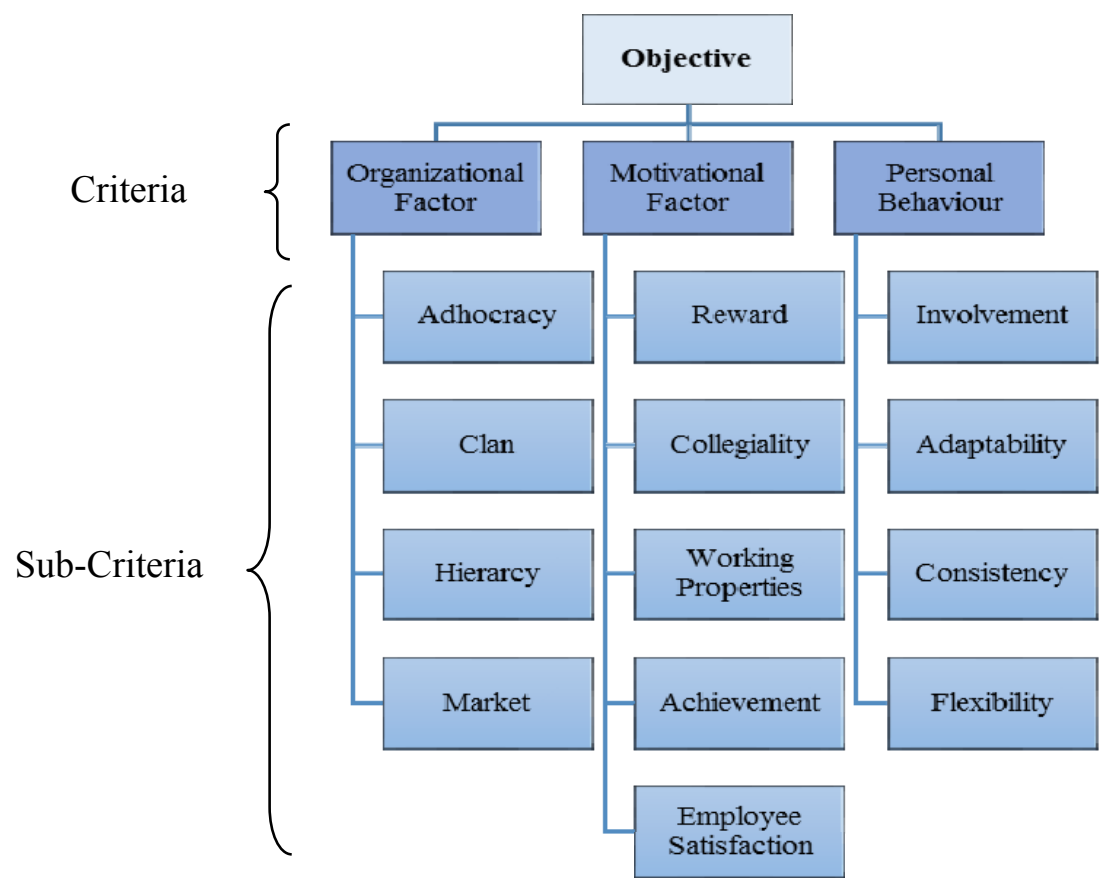

Figure 1. The hierarchical function of the criteria and sub-criteria

\section{Definition of Main Criteria}

Knowing how / why to conduct employees in organization is crucial. To do so, there are various main factors and sub-factors that affect these main factors in the organization which are explained below in detail.

Motivational Factor (MF): Motivation is a factor which affects the employee to maintain their work or goal in an organization. 
Organizational Factor $(\mathrm{OF})$ : The organization structure is the framework used by companies to present their authorities, communication, and point of view.

Personnel Behavior Factor (PB): Employee behavior refers to how employees respond to certain conditions in the workplace. As many facts determine the individual's behavior in the workplace as employees are shaped by organizational culture.

\section{Definition of Sub-Criteria}

For each criteria are explained below.

Adhocracy (OF1): This is the opposite of hierarchy. In an organization the structure of encouraging innovation, risk taker, growth oriented are dominant. The employees are able to adapt to changing conditions quickly, react fast, and stressing on individual initiative. Innovation in industry and competitiveness are also expected from the employees.

Clan (OF2): The name of the clan comes from a family structure. This factor is one of the most collaborative but less competitive one. The employees possess the common goals, views, and compromise, and also have a flexible structure.

Hierarchy (OF3): Here, rules, structure, control, procedure take part in the organization. It is clear that what the employee can do or not. Formal policies and rules that keep the organization together are crucial. This structure is common in the huge organizations and state institutions.

Market (OF4): Competitiveness is underlined not only for employees but also for corporations and market forces. It is crucial to achieve the goals and strain for employees. The performance of the employee is observed to punish or reward.

Reward (MF1): This sub-criterion refers to company branded reward, promotion / salary, course, and retirement.

Collegiality (MF2): This sub-criterion looks at teamwork, recognition/appreciation, praise and fairness/equality (Panagiotis, Alexandros, \& Polychronopoulos, 2014)

Working properties (MF3): This sub-criterion refers to power, clear goals, creativity possibilities, explicit tasks, skills exploitation and decision making (Panagiotis, Alexandros, \& Polychronopoulos, 2014).

Achievement (MF4): This sub-criterion refers to the significance/meaning of work, obtaining respect from work, obtaining satisfaction/self-esteem from work and good interpersonal relations (Panagiotis, Alexandros, \& Polychronopoulos, 2014)

Employee satisfaction (MF5): This sub-criterion refers to believing in manager, reward system, employee morale and motivation, and performance orientation.

Involvement (PB1): This refers to strengthening, business autonomy, talent improvement, taking part in decision.

Adaptability (PB2): Accepting the new roles, suggesting an alternative solution, opening to new ideas, focusing on customer, making easy transaction.

Consistency (PB3): This sub-criterion refers to core values, agreement, and coordination/integration (Iljins, Skvarciany, \& Gaile-Sarkane, 2015).

Main criterion there are different effecting sub-criteria which are shown in Figure 1. These subFlexibility (PB4): This is defined as spontaneity, change, openness, adaptability and responsiveness by Henri (2006). 


\section{Application of Fuzzy AHP}

The Fuzzy AHP method is applied for prioritizing critical factors of the organizational culture. In this study, we have three main criteria (motivational factor, organizational factor and personnel behavior factor) and thirteen sub-criteria (adhocracy, clan, hierarchy, market, reward, collegiality, working properties, achievement, employee satisfaction, involvement, adaptability, consistency, flexibility). The hierarchical function of the criteria and sub-criteria is demonstrated in Figure 1.

Determining Weights of Main Criteria: We have three experts who evaluated these main criteria. According to their evaluation, the matrix of the main criteria is shown in Table 3 and 4 (Step 1, 2, 3).

Table 2

Evaluation Matrix with Respect to the Goal

\begin{tabular}{lccc|ccc}
\hline & \multicolumn{3}{c|}{ Matrix in linguistic terms } & \multicolumn{3}{c}{ Matrix in fuzzy terms } \\
\hline & OF & MF & PB & OF & MF & PB \\
\hline OF & $*$ & & IV & $(1,1,1)$ & $(1 / 5,1 / 3,1 / 1)$ & $(3,4,5)$ \\
MF & MI & $*$ & DI & $(1,3,5)$ & $(1,1,1)$ & $(5,7,9)$ \\
PB & & & $*$ & $(1 / 5,1 / 4,1 / 3)$ & $(1 / 9,1 / 7,1 / 5)$ & $(1,1,1)$ \\
\hline
\end{tabular}

Table 3

Comparison Matrix of the Main Factor

\begin{tabular}{cccc}
\hline Main Criteria & OF & MF & PB \\
\hline OF & $(1,1,1)$ & $(1 / 5,1 / 3,1 / 1)$ & $(3,4,5)$ \\
MF & & $(1,1,1)$ & $(5,7,9)$ \\
PB & & & $(1,1,1)$ \\
\hline
\end{tabular}

The geometric mean of fuzzy comparison value of all main factors is computed by $4^{\text {th }}$ equation, and the solution of the calculation is presented in Table 5 (Step 4).

Table 4

The Geometric Mean of Fuzzy Comparison Value of Main Factor

\begin{tabular}{llll}
\hline \multicolumn{1}{c}{} & & \\
\hline OF & $\tilde{r}_{\mathrm{i}}$ & & \\
$\mathrm{MF}$ & .843433 & 1.100642 & 3.556976 \\
$\mathrm{~PB}$ & 1.709976 & 2.758924 & .40548 \\
TOTAL & .281144 & .329317 & 5.672349 \\
\hline
\end{tabular}

In the next step (Step 5) $\widetilde{W}_{i}$ is calculated as shown in Table 6.

Table 5

Relative Fuzzy Weights of Each Main Factor

\begin{tabular}{llll}
\hline Main criteria & $\tilde{W}_{i}$ & & \\
\hline OF & .148692 & .262753 & .603261 \\
MF & .301458 & .65863 & 1.254834 \\
PB & .049564 & .078617 & .143049 \\
\hline
\end{tabular}

Finally, the average of the fuzzy weight of the criterion is found in Step 6, and then non-fuzzy weight of all main factors $\left(M_{i}\right)$ is normalized in the last step as displayed in Table 7. 
Table 6

Averaged and Normalized Relative Weight of Main Factors

\begin{tabular}{lll}
\hline Main Factors & $M_{i}$ & normalized $\left(N_{i}\right)$ \\
\hline OF & .338235 & .290 \\
MF & .738307 & .633 \\
PB & .09041 & .077 \\
& 1.166953 & \\
\hline
\end{tabular}

Determining Weights of Sub-Criteria with respect to Main Criteria: The same steps are valid for the sub-criteria. However, sub-criteria should be pair wise compared in connection with main criteria. For weight calculation the same procedure is valid for all sub-criteria. Table 8 and 9 presents the comparison matrices of the main factor and sub-criteria with respect to MF main criteria.

Table 7

Comparison Matrices of the Main Factor (MF)

\begin{tabular}{llllll}
\hline \multicolumn{5}{c}{ Matrix in linguistic terms } \\
\hline MF & MF1 & MF2 & MF3 & MF4 & MF5 \\
\hline MF1 & $*$ & & & \\
MF2 & MI & $*$ & $*$ & SI & MI \\
MF3 & DI & IV & & $*$ & $*$ \\
MF4 & SI & SI & SI & $*$ \\
MF5 & SI & IV & & & \\
\hline
\end{tabular}

Table 8

Comparison Matrices of Sub-Criteria with Respect to MF Main Criteria

\begin{tabular}{llllll}
\hline \multicolumn{2}{l}{ Matrix in fuzzy terms } & & & & \\
\hline MF1 & MF2 & MF3 & MF4 & MF5 \\
\hline$(1,1,1)$ & $(1 / 5,1 / 3,1 / 1)$ & $(1 / 9,1 / 7,1 / 5)$ & $(1 / 7,1 / 5,1 / 3)$ & $(1 / 7,1 / 5,1 / 3)$ & 5 \\
$(1,3,5)$ & $(1,1,1)$ & $(1 / 7,1 / 6,1 / 5)$ & $(1 / 5,1 / 3,1 / 1)$ & $(1 / 5,1 / 4,1 / 3)$ & 4 \\
$(5,7,9)$ & $(5,6,7)$ & $(1,1,1)$ & $(3,5,7)$ & $(1,3,5)$ & 1 \\
$(3,5,7)$ & $(3,5,7)$ & $(1 / 7,1 / 5,1 / 3)$ & $(1,1,1)$ & $(1 / 7,1 / 5,1 / 3)$ & 3 \\
$(3,5,7)$ & $(3,4,5)$ & $(1 / 5,1 / 3,1 / 1)$ & $(3,5,7)$ & $(1,1,1)$ & 2 \\
\hline
\end{tabular}

The weight vector is computed as $\mathrm{W}_{\mathrm{mf}}=(0.043 ; 0.076 ; 0.469 ; 0.125 ; 0.287)$.

Table 10 and 11 demonstrates the comparison matrices of the main factor and sub-criteria with respect to OF main criteria.

Table 9

Comparison Matrices of the Main Factor (OF)

\begin{tabular}{lllll}
\hline \multicolumn{5}{c}{ Matrix in linguistic terms } \\
\hline OF & OF1 & OF2 & OF3 & OF4 \\
\hline OF1 & $*$ & $*$ & & \\
OF2 & MI & IV & $*$ & $*$ \\
OF3 & IV & DI & IV \\
OF4 & EI & IV & \\
\hline
\end{tabular}


Table 10

Comparison Matrices of Sub-Criteria with Respect to of Main Criteria

\begin{tabular}{|c|c|c|c|c|}
\hline \multicolumn{4}{|c|}{ Matrix in fuzzy terms } & \multirow{2}{*}{ Rank } \\
\hline OF1 & OF2 & OF3 & OF4 & \\
\hline$(1,1,1)$ & $(1 / 5,1 / 3,1 / 1)$ & $(1 / 7,1 / 6,1 / 5)$ & $(1 / 9,1 / 9,1 / 7)$ & 4 \\
\hline$(1,3,5)$ & $(1,1,1)$ & $(1 / 5,1 / 4,1 / 3)$ & $(1 / 9,1 / 7,1 / 5)$ & 3 \\
\hline$(5,6,7)$ & $(3,4,5)$ & $(1,1,1)$ & $(1 / 3,1 / 2,1)$ & 2 \\
\hline$(7,9,9)$ & $(5,7,9)$ & $(1,2,3)$ & $(1,1,1)$ & 1 \\
\hline
\end{tabular}

The weight vector is computed as $\mathrm{W}_{\text {of }}=(0.052 ; 0.096 ; 0.319 ; 0.534)$

Table 12 and 13 presents the comparison matrices of the main factor and sub-criteria with respect to $\mathrm{PB}$ main criteria.

Table 11

Comparison Matrices of the Main Factor (PB)

\begin{tabular}{lllll}
\hline \multicolumn{5}{c}{ Matrix in linguistic terms } \\
\hline PB & PB1 & PB2 & PB3 & PB4 \\
\hline PB1 & $*$ & IV & SI \\
PB2 & $*$ & $*$ & MI \\
PB3 & SI & IV \\
PB4 & MI & & $*$ \\
\hline
\end{tabular}

Table 12

Comparison Matrices of Sub-Criteria with Respect to PB Main Criteria

\begin{tabular}{lllll}
\hline \multicolumn{4}{c}{ Matrix in fuzzy terms } & \multicolumn{2}{c}{ Rank } \\
\hline PB1 & PB2 & PB3 & PB4 & \\
$(1,1,1)$ & $(1,2,3)$ & $(1 / 5,1 / 3,1 / 1)$ & $(3,5,7)$ & 2 \\
$(1 / 3,1 / 2,1)$ & $(1,1,1)$ & $(1 / 7,1 / 5,1 / 3)$ & $(1,3,5)$ & 3 \\
$(1,3,5)$ & $(3,5,7)$ & $(1,1,1)$ & $(7,8,9)$ & 1 \\
$(1 / 7,1 / 5,1 / 3)$ & $(1 / 5,1 / 3,1 / 1)$ & $(1 / 9,1 / 8,1 / 7)$ & $(1,1,1)$ & 4 \\
\hline
\end{tabular}

The weight vector is computed as $\mathrm{W}_{\mathrm{pb}}=(0.256 ; 0.137 ; 0.549 ; 0.058)$

Final ranking of main and sub criteria for the organizational culture is represented in Table 14 and Figure 1.

Table 13

Final Ranking of Main and Sub Criteria for the Organizational Culture

\begin{tabular}{|c|c|c|c|c|c|}
\hline Main-Criteria & Local Importance & Sub-Criteria & Local Importance & Global Importance & Rank \\
\hline \multirow{4}{*}{ OF } & \multirow{4}{*}{.29} & OF1 & .052 & .015 & 11 \\
\hline & & OF2 & .096 & .028 & 8 \\
\hline & & OF3 & .319 & .093 & 4 \\
\hline & & OF4 & .534 & .155 & 3 \\
\hline \multirow{5}{*}{ MF } & \multirow{5}{*}{.633} & MF1 & .043 & .027 & 9 \\
\hline & & MF2 & .076 & .048 & 6 \\
\hline & & MF3 & .469 & .297 & 1 \\
\hline & & MF4 & .125 & .079 & 5 \\
\hline & & MF5 & .287 & .182 & 2 \\
\hline \multirow{4}{*}{ PB } & \multirow{4}{*}{.077} & PB1 & .256 & .020 & 10 \\
\hline & & $\mathrm{PB} 2$ & .137 & .011 & 12 \\
\hline & & PB3 & .549 & .042 & 7 \\
\hline & & PB4 & .058 & .004 & 13 \\
\hline
\end{tabular}




\section{Global Importance}

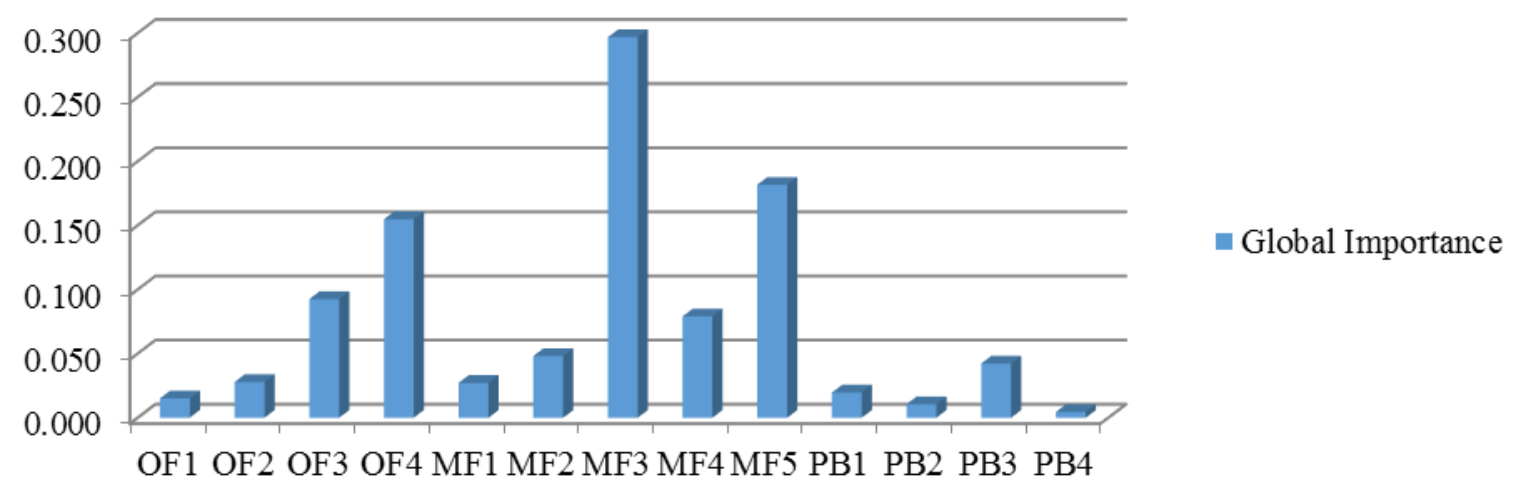

Figure 1. Final ranks of criteria

\section{Results and Discussion}

The fuzzy AHP is useful for decision-makers' choices to prioritize and rank the factors in order to get data about the significance of the criteria. This approach is applied, and there are three main criteria in this paper represented motivational factor such as organizational factor and personnel behavior factor, and thirteen sub-criteria (adhocracy, clan, hierarchy, market, reward, collegiality, working properties, achievement, employee satisfaction, involvement, adaptability, consistency, flexibility).

The weights of the main criteria are demonstrated in Table 7, and the weights of the subcriteria are calculated as WPB, WMF, and WOF. If the weights of the sub-criteria and the weights of the main criteria is multiplied, the global importance can be calculated which is shown in Figure 1. As it can be seen clearly in Figure 1, MF3 (working properties) is the most important for the successful organizational culture. MF5 (employee satisfaction), OF4(market), and OF3 (hierarchy) are the other factors that are more effective for the successful organizational culture.

When we investigate each sub-criteria according to Table 14, the result of the comparison the sub-criteria matrices with respect to OF (Organizational factor) main criteria shows that the ranking is OF4 (Market), OF3 (Hierarchy), OF2 (Clan), OF1 (Adhocracy). In Table 14, the result of the comparison the sub-criteria matrices with respect to $\mathrm{PB}$ (Personnel behavior) main criteria shows that the ranking is PB3 (Consistency), PB1 (Involvement), PB2 (Adaptability), PB4 (Flexibility). For the final sub-criteria MF (Motivational factor), the rank is MF3 (Working properties), MF5 (Employee satisfaction), MF4 (Achievement), MF2 (Collegiality), MF1 (Reward).

\section{Conclusion}

Every organization has own unique structure just like humans that show the organizational culture. There can be many factors affect the success; here what we have to do is prioritizing critical factors. In this study, we have three main criteria and thirteen sub-criteria. Some criteria are intangible. Decision makers' choices have fuzzy logic; hence, we used Fuzzy AHP to 
prioritize the criteria in the study. According to the results, the most effective criteria are working properties, employee satisfaction, market and hierarchy, respectively. In order to have a more successful organization, the company should improve the working properties with having creativity possibilities, and explicit tasks. Firms can provide more moral and performance orientation for the employees' satisfaction. In future research, different methods and further analysis can be applied.

\section{Rerefences}

Acar, A. Z. (2012). Organizational culture, leadership styles and organizational commitment in Turkish logistics industry. Procedia - Social and Behavioral Sciences, 58, 217-226.

Aktaş, E., Çiçek, I., \& Kıyak, M. (2011). The effect of organizational culture on organizational efficiency: The moderating role of organizational environment and CEO values. Procedia-Social and Behavioral Sciences, 24, 1560-1573.

Anna, Y. K., Igor, B. A., \& Natalia, N. K. (2015). Organizational culture in focus of measurements. Procedia-Social and Behavioral Sciences, 166, 246-253.

Arditi, D., Nayak, S., \& Damci, A. (2017). Effect of organizational culture on delay in construction. International journal of project management, 35(2), 136-147.

Belias, D., Koustelios, A., Vairaktarakis, G., \& Sdrolias, L. (2015). Organizational Culture and Job Satisfaction of Greek Banking Institutions. Procedia - Social and Behavioral Sciences, 175, 314-323.

Henri, J. F. (2006). Organizational culture and performance measurement systems. Accounting, Organizations and Society, $31(1), 77-103$

Hsieh, M. C., Wang, E. M. Y., Lee, W. C., Li, L. W., Hsieh, C. Y., Tsai, W., \& Liu, T. C. (2018). Application of HFACS, fuzzy TOPSIS, and AHP for 1dentifying 1mportant human error factors in emergency departments in Taiwan. International Journal of Industrial Ergonomics, 67, 171-179.

Iljins, J., Skvarciany, V., \& Gaile-Sarkane, E. (2015). Impact of organizational culture on organizational climate during the process of change. Procedia - Social and Behavioral Sciences, 213, 944-950.

Lapiņa, I., Kairiša, I., \& Aramina, D. (2015). Role of organizational culture in the quality management of university. Procedia - Social and Behavioral Sciences, 213, 770-774.

Mardani, A., Jusoh, A., MD Nor, K., Khalifah, Z., Zakwan, N., \& Valipour, A. (2015). Multiple criteria decision-making techniques and their applications - A Review of the Literature from 2000 to 2014. Economic Research-Ekonomska Istrazivanja, 28(1), 516-571.

Nyimbili, P. H., Erden, T., \& Karaman, H. (2018). Integration of GIS, AHP and TOPSIS for earthquake hazard analysis. Natural Hazards, 92(3), 1523-1546.

Panagiotis, M., Alexandros, S., \& George, P. (2014). Organizational culture and motivation in the public sector . The case of the city of Zografou. Procedia Economics and Finance, 14(14), 415-424.

Pätäri, E., Karell, V., Luukka, P., \& Yeomans, J. S. (2018). Comparison of the multicriteria decision-making methods for equity portfolio selection: The U.S. evidence. European Journal of Operational Research, 265(2), 655-672.

Rus, M., \& Rusu, D. O. (2015). The organizational culture in public and private institutions. Procedia - Social and Behavioral Sciences, 187, 565-569.

Schneider, B., Brief, A. P., \& Guzzo, R. A. (1996). Creating a climate and culture for sustainable organizational change. Organizational Dynamics, 24(4), 7-19.

Stock, G. N., McFadden, K. L., \& Gowen III, C. R. (2007). Organizational culture, critical success factors, and the reduction of hospital errors. International Journal of Production Economics, 106(2), 368-392.

Warrick, D. D., Milliman, J. F., \& Ferguson, J. M. (2016). Building high performance cultures. Organizational Dynamics, 45(1), 64-70.

Zerella, S., von Treuer, K., \& Albrecht, S. L. (2017). The Influence of office layout features on employee perception of organizational culture. Journal of Environmental Psychology, 54, 1-10. 